26. Gruen RL, Bailie RS, et al. Improving access to specialist care for remote Aboriginal communities: Evaluation of a specialist outreach service. Med J Aust 2001; 174: 507-511.

27. Cunningham M, Silove D. Principles of treatment and service development for torture and trauma survivors. International
Handbook of Traumatic Stress Syndromes. Wilson JP, Raphael B (editors). New York: Plenum Press, 1993; 751762.

28. Harris M, Furler J. How can primary care increase equity in health? N S W Public Health Bull 2002; 13(3): 35-37.

\title{
THE HEALTH CARE DISADVANTAGES OF BEING OBESE
}

\author{
Wendy Pryor \\ Mansfield Pathology \\ Paddington, New South Wales
}

People who are obese are disadvantaged socially-in public places, in employment, and in health care. ${ }^{1-2}$ Many obese people are afraid of approaching health professionals and attending health facilities. Problems of access and lack of suitable facilities for obese people are a problem; however, the greatest impediment is the fear of encountering judgmental and discriminatory attitudes from health professionals about a patient's obesity.

Because of an increased risk of medical illnesses such as type 2 diabetes mellitus, hypertension, cardiovascular disease, stroke, sleep apnoea, gallbladder disease, and osteoarthritis, ${ }^{3}$ the need of obese people for medical care is great. However, the recommendation of weight loss as a primary therapy may compromise and delay the management of significant medical problems. This article describes the attitude of some health professionals towards obese patients, obese patients' views about health care, myths and realties about obesity, and suggests how health care for obese patients can be improved.

\section{ATTITUDES OF HEALTH PROFESSIONALS TOWARD OBESE PATIENTS}

Many studies have described how health care professionals may adopt a negative attitude towards obese patients. ${ }^{4-5}$ Medical practitioners and students often regard obese patients as ugly, sad, lacking in self-control, and difficult to manage. ${ }^{6-8}$ Nurses may be uncomfortable with obese patients and prefer not to care for them. ${ }^{9-10}$ Most health care professionals believe that obese patients are responsible for their obesity. ${ }^{11}$ These negative attitudes are readily perceived by obese patients. ${ }^{12}$

Health care professionals are often aware of poor health outcomes in the treatment of obesity; but, generally, they do not hold themselves responsible for the failure of positive health outcomes. While some health care professionals recognise the intrinsic difficulty of treating an obese patient, there is still a tendency to blame the patient for their failure to be slim. ${ }^{13-17}$

\section{OBESE PATIENTS' VIEWS ABOUT HEALTHCARE}

Medical publications have given little attention to the personal experiences of obese people with health care services. Internet sites dedicated to acceptance and support for obese people often display messages from individuals who have experienced discriminatory treatment in health care settings. A selection of messages posted on the Big Beautiful Women Downunder Internet site at www.dksc.ws/bbw, or on linked sites, are quoted here to give an indication of some expressed concerns.

\section{Consultations with general practitioners, specialists, or clinics}

'Without knowing my background, eating or exercise habits [the doctor] assumed me to be both slothful and a compulsive eater. [The doctor] showed no willingness to believe me when I explained I was neither. Like most fat people I have an almost encyclopaedic knowledge of the carbohydrate, fat, and caloric content of food.'

'I was perched half naked, legs dangling unsupported on your high narrow examination couch, trying to hold a tiny gown modestly over my large unfettered breast. I was far too embarrassed to be anything but hypertensive.'

'Over the past seven months I have been to two obesity specialists ... and neither of the waiting rooms had seating suitable for larger people.'

'All we really need are chairs without arms! Whenever I go for medical appointments, every single chair has arms.'

\section{Hospital admission}

'Gowns that cover one half of my body, beds so narrow you want to be careful not to roll over, thin mattresses that squish to almost nothing under my weight, and the best part of all, those damned bed pans.'

'Many [health professionals] can't help absorbing the prevailing attitudes of our society, which basically assume that if you are fat you are necessarily unhealthy and that you obviously haven't tried to do anything about itwhich is generally incorrect.'

'Women's magazines are the cheapest and most convenient form of waiting room literature, and these are generally mildly size-negative at best, and positively feral about [body size] at worst.'

'I haven't seen a doctor for a general check up at any time in my life. I have a strong dislike of being lectured and hectored and harassed and heckled about weight or treated like a particularly naughty three-year old with a penchant for sweets. I am so afraid [of health professionals] that I 
don't want to take steps to look after my health because of them.'

\section{MYTHS AND REALITIES ABOUT OBESITY}

Prejudicial attitudes about obesity commonly arise from popular myths. ${ }^{18}$

\section{Myth 1: Obese people are usually lazy and/or gluttonous}

Although lifestyle factors, including overeating and lack of exercise, can contribute significantly to weight gain, many factors determine a person's size. Genetic, metabolic, and other minimally-modifiable factors are involved. Two people can eat the same amount of food with different results in body weight and body composition; ${ }^{19}$ obese people do not necessarily eat more than lean people. In fact, obese people may need to eat considerably less to maintain their body weight. ${ }^{20}$

\section{Myth 2: Dieting is an effective way to reduce weight}

Only five per cent of patients dieting to achieve permanent weight loss will be successful and reap the associated health benefits. The health implications of failed attempts at dieting are numerous and include negative effects on both physical and psychological wellbeing. ${ }^{21}$ Relapse occurs in many subjects after $3-5$ years. ${ }^{22}$

\section{Myth 3: Health for the obese is best achieved through weight loss}

People who lose and regain weight (weight cycling) have a greater risk of dying, particularly from coronary heart disease, than those who maintain a relatively stable weight. ${ }^{23}$ Therefore, for most people, weight stability is likely to be more important than weight loss. ${ }^{20}$ The process of weight loss can produce a number of adverse effects such as tiredness, irritability, and mood swings; uncontrolled weight loss can cause serious metabolic disturbances, and very occasionally death. Experts advise that a healthy diet with adequate physical activity can produce immediate health benefits, ${ }^{23-24}$ which may be more beneficial than weight loss.

\section{HOW HEALTH CARE FOR OBESE PEOPLE CAN BE IMPROVED}

Health care professionals and students may need to reassess their attitude towards the obese; it is important to recognise that the medical needs of the patient take priority over the issue of weight.

Discreet enquiry regarding weight issues may open the door to a patient who wishes to discuss their weight but is afraid to do so. However, a patient's prior knowledge and experience in this area should first be explored and acknowledged. Their rights to accept or decline intervention or counselling must be respected. Anyone recommending weight loss treatments must be aware of the likely outcomes and unwanted effects of the treatment. As for any other major intervention, an obese patient should be able to give informed consent to any weight loss treatment.
For many obese patients, weight loss may not be the healthiest option. It may be preferable to facilitate selfacceptance by encouraging self-esteem, an active social life, a moderate exercise program, and healthy eating habits. Results are best measured in terms of health gains rather than kilograms lost. Obese patients should also be protected from exploitation by the diet industry.

In providing health care facilities, planners should consider designated size-friendly clinics with the same accessibility as that provided for mobility-impaired patients, including large restrooms wherever possible. It may be necessary to design some radiological and other diagnostic equipment to accommodate obese patients. Even small and inexpensive concessions could be made to ease the stress on obese people in health care facilities. The first may be to provide one or two sturdy, armless chairs or a well-supported couch in the waiting room. Health-positive, size-neutral literature in waiting roomsand a large sphygmomanometer cuff to ensure accurate blood-pressure readings - are other simple but potentially helpful measures.

\section{CONCLUSIONS}

It has been said that 'To treat disease in the obese is obviously good. To treat simple obesity as a disease may be another matter entirely'. ${ }^{25}$ We need to focus on the medical and emotional needs of the obese patient rather than on the size of the patient. This may help to improve the uncomfortable and potentially harmful relationships between the obese patient and the health care provider. Perhaps then the obese person may be less fearful of seeking health care.

\section{REFERENCES}

1. Wadden T, Stunkard A. Social and psychological consequences of obesity. Ann Intern Med 1985; 103 (6): 1062-7.

2. Rand C, Macgregor A. Morbidly obese patients' perceptions of social discrimination before and after surgery for obesity. South Med J 1990; 83(12): 1390-5.

3. Khaodhiar L, McCowen K, Blackburn G. Obesity and its comorbid conditions. Clinical Cornerstone 1999; 2(3): 17-31.

4. Agell G, Rothblum E. Effects of clients' obesity and gender on the therapy judgments of psychologists. Prof Psychol Res Pract 1991; 22: 223-229.

5. Price J, Desmond S, Krol R, Snyder F, O’Connell J. Family practice physicians' beliefs, attitudes, and practices regarding obesity. Am J Prev Med 1987; 3(6): 339-45.

6. Rothblum E. The stigma of women's weight: Social and economic realities. Feminism de Psychology 1992; 2: 61-73.

7. Loomis G, Connolly K, Clinch C, Djuric D. Attitudes and practices of military family physicians regarding obesity. Mil Med 2001; 166(2): 121-5.

8. Wright J. Female nurses' perceptions of acceptable female body size: An exploratory study. J Clin Nurs 1998; 7(4): 307-15.

9. Bagley C, Conklin D, Isherwood R, Pechiulis D, Watson L. Attitudes of nurses toward obesity and obese patients. Percept Mot Skills 1989; 68: 954.

10. Maroney D, Golub S. Nurses' attitudes toward obese persons and certain ethnic groups. Percept Mot Skills 1992; 75: 387-391. 
11. Culbertson M, Smolen M. Attitudes toward personalities and lifestyles of obese adults. Journal of Nursing Education 1999; 38(2): 84

12. Garner C, Nicol G. Comparison of male and female nurses' attitudes toward obesity. Percept Mot Skills 1998; 86(3): 1442.

13. Hoppe R, Ogden J. Practice nurses' beliefs about obesity and weight related interventions in primary care. Int J Obes Relat Metab Disord 1997; 21(2): 141-6.

14. Maiman L, Wang V, Beckler M, Finlay J, Simonson M. Attitudes toward obesity and the obese among professionals. J Am Diet Assoc 1979; 74: 331-336.

15. Campbell K, Engel H, Timperio A, Cooper C, Crawford D. Obesity management: Australian general practitioners' attitudes and practices. Obes Res 2000; 8(6): 459-66.

16. Campbell K, Crawford D. Management of obesity: Attitudes and practices of Australian dietitians. Int J Obes Relat Metab Disord 2000; 24 (6): 701-10.

17. Jeffcoate W. Obesity is a disease: Food for thought. Lancet 1998; 351(9106): 903-904.

18. Rothblum E. Women and weight: Fad and fiction. J Psychol 1990; 124(1): 5-24.
19. Bouchard C, Tremblay A, Despres J, Nadeau A, Lupietn P, Theriault G, Dussalt J, Moorjani S, Pinault S, Fournier G. The response to long term overfeeding in identical twins. $N$ Eng J Med 1990; 322: 1477-1482.

20. Garner D, Wooley S. Confronting the failure of behavioral and dietary treatments for obesity. Clin Psychol Rev 1991; 11: 729-780.

21. Kirkland L, Anderson R. Achieving healthy weights. Can Fam Phys 1993; 39:157-8, 161-2.

22. Miller W. How effective are traditional dietary and exercise interventions for weight loss? Medicine \& Science in Sports \& Exercise 1999; 31(8): 1129-34.

23. Berg F. The health risks of weight loss. The Health Risks of Obesity. Healthy Living Institute. Hettinger, ND: Decker Periodicals, 1993.

24. Ernsberger P, Haskew P. Rethinking obesity: An alternative view of its health implications. J Obes Weight Regulation 1987; 6(2).

25. Fitzgerald F. The problem of obesity. Аnпи Rev Med 1981; 32: 221-31.

\section{CONSUMERS FIRST: PARTICIPATING IN THE SYSTEM}

\section{Elizabeth McDonald}

Croydon, New South Wales

As a retired social worker, and a person with a severe physical disability, I have had the opportunity to view the health system from both points of view. This article gives a personal reflection on the contribution that consumers might make to address the inequalities evident in health services.

\section{A PERSONAL ENCOUNTER}

It seems to me that, as in most organisations, health services are 'compartmentalised'. Each section, department, ward, or service, has its own brief; if the individual does not fit into that particular brief then they can have difficulty in accessing the assistance they need. My own quest to be weighed falls into this category of problems. I must say that this has not become an obsession, and that I may well have succeeded in being weighed if I had persevered.

To explain, I use an electric wheelchair and am not able to transfer without a lifter. Some years ago I was able to be weighed at a facility by a friend — of one of the health professionals I was seeing at the time-during her lunch hour. This solved the problem at the time. However, I was conscious that, had there been an accident of some sort, I was not a 'patient' of the facility and this could have caused difficulties for the person concerned. At the time I had to have some dietary advice and, as I had private health cover for extras, I began to attend a private clinic that also did not have the facility to weigh me. The dietician and I tried the hospital kitchen with the plan to weigh me in the wheelchair and then subtract the weight of the chair. Unfortunately, the new kitchen scales were not suitable.
My next attempt, a couple of years later, was when I had a short inpatient admission that I knew would involve a transfer from chair to bed. Armed with a request from my doctor I requested that, when I was being transferred, I might be weighed on a weighing chair. No luck again. There was no weighing chair on the ward and the staff were too busy to borrow one. My latest attempt has been to enquire of another community health professional if there was some way I could be weighed by someone in her community health service. Well no. I would have to see the dietician for that service.

I present this experience as an illustration of the difficulties faced by a person with a disability in accessing a simple service - to be weighed. Such a problem would be even greater if I did not speak English and/or had no knowledge of the health system. Although the service would be simple to provide, the complexity of the 'system' has prevented access.

\section{THE INTERFACE WITHTHE CONSUMER INTHE COMMUNITY}

This same topic of compartmentalised responsibilities is evident in the interface between health and other community services. This interface was described in a 1996 report for the Consumers First Project. ${ }^{1}$ The report examined the problems associated with the different areas of care, including health services (both hospital and community based), home and community care services, Department of Community Services, and nongovernmental service providers. Twenty-six case studies cover a wide range of situations, ages, ethnicity, and disability. They show how differing services, responsibilities, and lack of communication between and within services can affect the outcome for consumers. 